\title{
Fatal peptic ulcer complications and the use of non-steroidal anti-inflammatory drugs, aspirin, and corticosteroids
}

\author{
DAVID A HENRY, ANNE JOHNSTON, ANNETTE DOBSON, JOHN DUGGAN
}

\begin{abstract}
Although non-steroidal anti-inflammatory drugs are known to cause peptic ulcer and its complications, controversy exists about the number of deaths from ulcer which are attributable to their use. A case-control study was therefore performed to determine whether prior use of non-steroidal and other antiinflammatory compounds was associated with an increased case fatality rate from complications of peptic ulcer. Non-steroidal anti-inflammatory drugs were used by $39 \%$ of a series of 80 patients who had died from peptic ulcer complications and by $37 \%$ of 160 controls who were survivors matched for sex, age, ulcer site, and nature of complication (odds ratio 1.1; $95 \%$ confidence interval 0.6 to $2 \cdot 1$ ). Similarly, the rates of prior use of aspirin by cases and controls were almost identical (odds ratio 1.2 ; $95 \%$ confidence interval 0.5 to 1.9 ). Thus neither nonsteroidal anti-inflammatory drugs nor aspirin.were associated with increased case fatality rates from peptic ulcer complications. In contrast, corticosteroids were associated with an increased mortality (odds ratio $4 \cdot 2 ; 95 \%$ confidence interval 0.9 to 25.6). Although this increase in the estimated relative risk was not statistically significant, a review of the case records indicated that most deaths in steroid users were due to serious sepsis, indicating that there might be a causal association between use of the drugs and the mode of death.
\end{abstract}

\section{Introduction}

Non-steroidal anti-inflammatory drugs are among the most commonly prescribed drugs. They are often used to treat minor self

\footnotetext{
Discipline of Clinical Pharmacology, University of Newcastle, Royal Newcastle Hospital, Newcastle, NSW 2300, Australia

DAVID A HENRY, MB;, MRCP, senior lecturer in clinical pharmacology ANNE JOHNSTON, RN, research assistant

Department of Statistics, University of Newcastle, NSW 2308, Australia ANNETTE DOBSON, MSC, PHD, professor of biostatistics

Royal Newcastle Hospital, NSW 2300, Australia

JOHN DUGGAN, MD, FRACP, director, department of gastroenterology

Correspondence to: Dr Henry.
}

limiting disorders, and any benefits of widespread use must be weighed carefully against the costs. Serious gastrointestinal toxicity, in particular bleeding or perforated peptic ulcer, is the most common side effect of these drugs that is reported voluntarily to national monitoring centres. ${ }^{1}$ In determining risk spontaneous reports are of limited value, and formal epidemiological studies are necessary.

One measure of cost is the number of deaths directly attributable to the use of non-steroidal anti-inflammatory drugs. In the United Kingdom published estimates have varied from 200 to over 3000 deaths each year. ${ }^{23}$ The higher estimate was based on an analysis of prior drug use by patients who had died of bleeding or perforated ulcers. ${ }^{3} \mathrm{~A}$ fuller report from the same authors provided information on drug use by patients who died from, or required surgery for, complications of ulcer. ${ }^{4}$ This report showed an unexpectedly high level of use of non-steroidal anti-inflammatory drugs by patients who died compared with those who survived, raising the possibility that the drugs increase not only the chance of developing ulcer complications but also the risk of dying of these disorders. An increase in case fatality rate might be due to a direct effect of the drugs - for example, on bleeding time or on renal function-or to a higher prevalence of other serious diseases among users of these drugs, making them more likely to fare badly after haemorrhage from, or perforation of, a peptic ulcer. The hypothesis of an increased case fatality rate was not supported by a multivariate analysis of factors determining the outcome after gastrointestinal bleeding, although that study included many patients without peptic ulcers and several who had bled while in hospital for other reasons. ${ }^{5}$

The controversy about the number of fatal peptic ulcer complications that can be attributed to non-steroidal anti-inflammatory drugs needs to be settled. We therefore conducted a case-control study to determine whether their use was associated with an increased case fatality rate from peptic ulcer complications in patients admitted to hospitals in Newcastle, New South Wales. This study also enabled us to examine the roles of aspirin and corticosteroids.

\section{Subjects and methods}

Since 1980 the Hunter health statistics unit has collected and stored information on all patients admitted to hospitals in the Hunter region of New 
South Wales. For each patient the information includes demographic data, the mode of discharge from hospital (died, discharged home, transferred, etc), and up to five discharge diagnoses. The greater Newcastle area has a population of about 390000 (1981 census) and is served by four public hospitals. Between January 1980 and June 1986, 1003 patients were admitted to these hospitals with a diagnosis of haemorrhage from, or perforation of, a peptic ulcer. The notes of all patients who had died during their hospital admission and whose records contained any mention of peptic ulcer complications in the discharge diagnoses were reviewed. Eighty one patients had died after admission to hospital with a primary diagnosis of complicated peptic ulcer (case fatality rate $8 \cdot 1 \%$ ). The case fatality rate was higher in patients aged over $60(12 \cdot 1 \%)$ and was higher after perforation $(12 \cdot 4 \%)$ than after haemorrhage $(7 \cdot 4 \%)$. Each fatal case was matched with two controls, who were patients who had survived a bleeding or perforated ulcer within two years of the case. Controls were matched with cases for age (to within five years), sex, site of ulcer (gastric or duodenal), and the nature of the complication (haemorrhage or perforation). The clinical notes from all cases and controls were examined to identify all drugs which had been taken during the week before admission to hospital. Although drug use was determined retrospectively, we thought it unlikely that this would introduce major bias in this study because of data we had already obtained from a casecontrol study with prospectively recruited patients with ulcers and controls without ulcers. In that study we had determined that information on the use of non-steroidal anti-inflammatory drugs and aspirin recorded in the hospital notes of 100 patients with ulcer complications admitted in 1985-6 was in $97 \%$ agreement with data obtained by structured interview and checked against the general practitioner's record. (D A Henry et al, 3rd international conference on pharmacoepidemiology, Minneapolis, 1987).

The measure of association between exposure to the drugs of interest and mortality from ulcer complications was the odds ratio with its $95 \%$ confidence interval calculated for matched triplets by the method of Miettinen. ${ }^{6}$ With 80 cases and 160 controls and a predicted prevalence of use of non-steroidal anti-inflammatory drugs of about $40 \%$ the study had a power of approximately 0.7 to detect as significant $(\alpha=0.05)$ a relative risk of 2.0 or above. This was considered sufficient to discriminate between the extremes of the published estimates of attributable mortality.

\section{Results}

Eighty patients who died from a bleeding or perforated ulcer were successfully matched for all variables. The average age of cases was $\mathbf{6 8 . 7}$ (range 40-90) years and of controls $68.3(39-88)$ years; $71 \%$ of cases and controls were men, $44 \%$ had bleeding gastric ulcers, $25 \%$ bleeding duodenal ulcers, $21 \%$ perforated duodenal ulcers, and $10 \%$ perforated gastric ulcers.

There was no evidence that use of non-steroidal anti-inflammatory drugs was associated with an increased mortality from complications of peptic ulcer. On admission to hospital non-steroidal anti-inflammatory drugs were being taken by similar proportions of cases and controls and the odds ratio was close to 1 . Likewise, there was no evidence that aspirin use increased the

TABLE I-Use of anti-inflammatory drugs by cases and controls. Results are numbers (and percentages) of users*

\begin{tabular}{|c|c|c|c|}
\hline Drugs & $\begin{array}{c}\text { Cases } \\
(\mathrm{n}=80)\end{array}$ & $\begin{array}{l}\text { Controls } \\
(n=160)\end{array}$ & $\begin{array}{l}\text { Odds ratio } \\
\text { (95\% confidence } \\
\text { interval) }\end{array}$ \\
\hline $\begin{array}{l}\text { Non-steroidal anti-inflammatory drugs } \\
\text { Aspirin } \\
\text { Corticosteroids }\end{array}$ & $\begin{array}{l}31(39) \\
19(24) \\
7(9)\end{array}$ & $\begin{array}{l}59(37) \\
34(21) \\
4(3)\end{array}$ & $\begin{array}{l}1 \cdot 1(0.6 \text { to } 2 \cdot 1) \\
1 \cdot 2(0.6 \text { to } 2 \cdot 4) \\
4 \cdot 2(0.9 \text { to } 25 \cdot 6)\end{array}$ \\
\hline
\end{tabular}

* Rates of multiple use recorded in the case records were as follows: more than one nonsteroidal anti-inflammatory drug: 3 cases and 7 controls; a non-steroidal anti-inflammatory drug with aspirin: 4 cases and 9 controls; a corticosteroid with a non-steroidal antiinflammatory drug or aspirin: 5 cases and 3 controls. risk of death from peptic ulcer complications (table I). In the case of nonsteroidal anti-inflammatory drugs a separate analysis including only those patients over the age of 60 years provided a risk estimate close to that of the whole group (odds ratio $1.0,95 \%$ confidence interval 0.5 to 1.9 ).

In contrast, the use of corticosteroids was associated with a roughly fourfold increase in the risk of death. The estimate of the odds ratio for corticosteroids is imprecise because of small numbers. In view of the apparent increase in the case fatality rate with corticosteroid use we examined the clinical details of the cases who had used steroids before admission to hospital (table II). While we cannot distinguish with certainty between the effects of steroid treatment and the serious underlying diseases which were the indications for the treatment, the fact that four of the seven deaths were due to overwhelming infection suggests that the drugs themselves may have adversely affected the outcome in these cases. In particular two of the three cases of fatal staphylococcal septicaemia were attributed to infected intravenous cannula sites.

As there was no difference between cases and controls in their use of nonsteroidal anti-inflammatory drugs we combined these groups to assess the strength of the associations between the matching criteria and prevalence of use of these drugs. As expected, users of non-steroidal anti-inflammatory drugs were older than non-users $(73 \cdot 4$ (range 51-90) years $v 65.8(39-88)$ years), and a higher proportion of women $(57 \%)$ than men $(30 \%)$ took the drugs. Use was almost as common in patients with duodenal ulcers $(35 \%)$ as in those with gastric ulcers $(\mathbf{4 0 \%})$, however, and was also unrelated to the nature of the complication (haemorrhage 39\%, perforation 35\%).

\section{Discussion}

It is important that the results of this study are interpreted correctly, and to do so we have to draw on other sources of data. As we did not include a control group without ulcers the data do not allow us to estimate the relative risk of developing complications of ulcers. Nevertheless, the data suggest that neither non-steroidal anti-inflammatory drugs nor aspirin are associated with increased case fatality rates from haemorrhage or perforation of peptic ulcers. In a separate study of patients with complications of peptic ulcer and individually matched controls without ulcers we estimated that the relative risk of developing bleeding or perforated ulcer for users of non-steroidal anti-inflammatory drugs over the age of 60 years lay between 2 and 3 (D A Henry et al, 3rd international conference on pharmacoepidemiology, Minneapolis, 1987). This is close to the range of values suggested by others. ${ }^{2}$ The prevalence of use of non-steroidal anti-inflammatory drugs in elderly subjects in the Newcastle region is over 20\% (D A Henry et al, 3rd international conference on pharmacoepidemiology, Minneapolis, 1987), and from this we can calculate that $20 \%$ to $30 \%$ of all cases of ulcer complications in subjects aged over 60 which result in hospitalisation are directly attributable to the use of non-steroidal anti-inflammatory drugs. The importance of the present work is that it indicates that this "attributable fraction" requires no further correction before being used to calculate attributable mortality. In 1984 in New South Wales (population 5.4 million) there were 1443 cases of complications of ulcers and 132 deaths in subjects aged 60 years and over. From our data we can calculate that non-steroidal antiinflammatory drugs were responsible for around 300 to 400 of these cases and 25 to 40 of the deaths. Corrected for differences in population size and prevalence of use of non-steroidal antiinflammatory drugs these figures are close to the estimate of $\mathbf{2 0 0}$ attributable deaths yearly in the United Kingdom published by Somerville et al. ${ }^{2}$ Similar calculations for aspirin, which approximately doubles the risk of ulcer complications ${ }^{78}$ but appears from

TABLE II-Details of patients treated with corticosteroids who died after developing complications of peptic ulcer

\begin{tabular}{|c|c|c|c|c|c|}
\hline Case No & $\begin{array}{c}\text { Sex and age } \\
\text { (years) }\end{array}$ & $\begin{array}{l}\text { Ulcer site and } \\
\text { complication }\end{array}$ & Steroid dose and duration & Indications for steroids & Causes of death \\
\hline $\begin{array}{l}1 \\
2 \\
3 \\
4 \\
5 \\
6 \\
7\end{array}$ & $\begin{array}{l}\text { M } 68 \\
\text { M } 62 \\
\text { M } 42 \\
\text { M } 71 \\
\text { M } 83 \\
\text { M } 71 \\
\text { F } 64\end{array}$ & $\begin{array}{l}\text { Bleeding DU } \\
\text { Bleeding GU } \\
\text { Perforated GU } \\
\text { Bleeding GU } \\
\text { Bleeding GU } \\
\text { Bleeding GU } \\
\text { Perforated DU }\end{array}$ & $\begin{array}{l}\text { Prednisolone } 10 \mathrm{mg} / \text { day "for years" } \\
\text { Prednisolone } 5 \mathrm{mg} / \text { day for } 5 \text { years } \\
\text { Prednisolone } 45 \mathrm{mg} / \text { day } \\
\text { Dexamethasone } 6 \mathrm{mg} / \text { day for } 7 \text { weeks } \\
\text { Dexamethasone } 16 \mathrm{mg} / \text { day for } 4 \text { months } \\
\text { Prednisolone } 10 \mathrm{mg} \text { on alternate days for } 6 \text { years } \\
\text { Prednisolone } 7 \mathrm{mg} / \text { day "for years" }\end{array}$ & $\begin{array}{l}\text { Obstructive airways disease } \\
\text { Obstructive airways disease } \\
\text { Pulmonary fibrosis } \\
\text { Cerebral tumour } \\
\text { Cerebral tumour } \\
\text { Haemolytic anaemia } \\
\text { Rheumatoid arthritis }\end{array}$ & $\begin{array}{l}\text { Multiple problems after amputation for gangrene } \\
\text { Uncontrolled haemorrhage } \\
\text { Gross peritoneal sepsis and septicaemia } \\
\text { Staphylococcal septicaemia } \\
\text { Uncontrolled haemorrhage } \\
\text { Staphylococcal septicaemia } \\
\text { Staphylococcal septicaemia and meningitis }\end{array}$ \\
\hline
\end{tabular}

$\mathrm{DU}=$ duodenal ulcer; $\mathrm{GU}=$ gastric ulcer. 
this work not to alter the case fatality rate, suggest that each year about 170 cases and 16 deaths from ulcer complications are attributable to its use in New South Wales. This estimate is lower than for non-steroidal anti-inflammatory drugs because aspirin is regularly used less often by subjects in this age group in New South Wales (D A Henry et al, 3rd international conference on pharmacoepidemiology, Minneapolis, 1987).

The suggestion that corticosteroids increase the case fatality rate from complications of peptic ulcer is a data derived hypothesis and should be interpreted with caution. Furthermore, the estimate of the relative risk is approximate because of small numbers. Nevertheless, the possibility of a substantially increased case fatality rate for users of corticosteroids is supported by data from an extensive survey of gastrointestinal bleeding published by the American Society for Gastrointestinal Endoscopy.' Interestingly, in our study the epidemiological data were backed by clinical evidence that the patients who died had suffered from adverse events which in some instances could be ascribed to the direct effect of corticosteroids, in particular overwhelming infections. Especially notable were two cases of staphylococcal septicaemia which were thought to be due to infection of intravenous cannula sites and thus by implication were preventable. On the basis of a meta-analysis of prospective randomised trials Messer et al concluded that corticosteroid treatment roughly doubled the incidence of haemorrhage from peptic ulcers. ${ }^{10}$ If our estimate of an increased fatality rate is correct then the risk of users of steroids developing and subsequently dying from ulcer complications might be about eight times higher than for non-users. Although this is a substantial increase for the individual, in population terms it is a small risk because of the low prevalence of use of steroids in the community.

Of the anti-inflammatory drugs, aspirin and non-steroidal antiinflammatory drugs, particularly the latter, are the important causes of morbidity and mortality in the community. Unlike steroids their intrinsic toxicity is not high. Rather, difficulties arise because of their extraordinarily wide use. Epidemiologically the relation is dominated by a high prevalence of the risk factor rather than a high relative risk of the disease. Thus the main thrust of attempts to reduce morbidity and mortality from non-steroidal anti-inflammatory drugs in the community should be to limit their use rather than to attempt to lower relative risk further by widespread coprescription of agents designed to "protect" the gastrointestinal mucosa, such as prostaglandins, sucralfate, or histamine $\mathrm{H}_{2}$ antagonists. While these measures may prove to have a role in a limited number of individuals, the greatest need is for more information on the factors which control prescribing decisions so that we can identify opportunities for intervention.

This study was supported by a grant from the National Health and Medical Research Council of Australia. We thank Professor R Gibberd for his help and advice.

\section{References}

1 Langman MJS. Peptic ulcer complications and the use of non-aspirin non-steroidal antiinflammatory drugs. Adverse Drug Reaction Bulletin 1986;120:448-51.

2 Somerville K, Faulkner G, Langman MJS. Non-steroidal anti-inflammatory drugs and bleeding peptic ulcer. Lancet 1986;i:462-4.

3 Blower AL, Armstrong CP. Ulcer perforation in the elderly and non-steroidal anti-inflammatory drugs. Lancet 1986;i:971.

4 Armstrong CP, Blower AL. Non-steroidal anti-inflammatory drugs and life threatening complications of peptic ulceration. Gut 1987;28:527-32.

5 Gilbert DA, Persing J, Silverstein FE, et al. National ASGE survey on upper gastrointestinal bleeding-Multivariate analysis of predictors of outcome. Gastrointest Endosc 1982;28:150-1.

6 Miettinen OS. Estimation of relative risk of individually matched series. Biometrics 1970;26:75-86.

7 Levy M. Aspirin use in patients with major upper gastrointestinal bleeding and peptic ulcer disease. N Engl f Med 1974;290:1158-62.

8 Coggon D, Langman MJS, Spiegelhalter D. Aspirin paracetamol and haematemesis and melaena. Gut 1982;23:340-4.

9 Silverstein FE, Gilbert DA, Tedesco FJ, et al. The National ASGE survey on upper gastrointestinal bleeding. II. Clinical prognostic factors. Gastrointest Endosc 1981;27:80-93.

10 Messer J, Reitman D, Sacks H, et al. Association of adrenocorticosteroid therapy and peptic ulcer disease. N Engl f Med 1983;309:21-4.

(Accepted 16 September 1987)

\title{
Cytopathogenic protein in filtrates from cultures of Propionibacterium acnes isolated from patients with Kawasaki disease
}

\author{
SHOBUN TOMITA, HIROHISA KATO, TAMOTSU FUJIMOTO, OSAMU INOUE, \\ YUKO KOGA, NORIKAZU KURIYA
}

\begin{abstract}
Propionibacterium acnes may have a role in Kawasaki disease. Filtrates from cultures of $P$ acnes isolated from cervical lymph node biopsy specimens and blood samples from patients with Kawasaki disease were studied and compared with samples from control subjects. After inoculation of human embryo liver cells with filtrates from the patients a cytopathogenic effect and vacuolation were seen. A specific cytopathogenic substance was found in only the filtrates of cultures from patients with Kawasaki disease; it was a protein of about isoelectric point 7.0 with a molecular weight of about 100000 daltons. The amount of IgG antibody to this cytopathogenic protein was measured by enzyme linked immunosorbent assay (ELISA) in serum samples taken from 63 patients in the acute phase of Kawasaki disease (mean $5 \cdot 2$ (SD 1.1) days after onset of illness), 45 in the subacute phase (mean 23.6 (3.3) days), and 51 in the convalescent phase (mean 18.5 (4.1) months) and from 102 control subjects matched for age. Titres of IgG antibody were significantly raised in patients with
\end{abstract}

Kawasaki disease, particularly in the acute and subacute phases of the illness, compared with in the control subjects.

Titres of IgG antibodies to cytopathogenic protein were found to be low in normal children below the age of 4 years but they increased with age thereafter. This may explain why outbreaks of Kawasaki disease, which is most common in children aged under 4, occur every three years.

\section{Introduction}

Kawasaki disease was first described in $1967,{ }^{1}$ and the number of patients affected is increasing not only in Japan but also in the United States, Europe, and Korea. ${ }^{2.5}$ Epidemiological studies have suggested either an infectious aetiology or an immune response to an infectious agent(s), ${ }^{6}$ but the exact cause of the disease has not been determined.

In 1983 we isolated Propionibacterium acnes from a lymph node biopsy specimen from a 6 year old boy with typical symptoms of 